\title{
Effects of tennis training on lipid metabolism and lipoproteins in recreational players
}

German Sports University Cologne, Institute of Sports Games, Carl-Diem-Weg 6, 50933 Cologne, Germany A Ferrauti $\mathrm{K}$ Weber H K Strüder

Correspondence to: Dr Ferrauti.

Accepted for publication 14 May 1997

\author{
Alexander Ferrauti, Karl Weber, Heiko K Strüder
}

\begin{abstract}
Objective-To investigate the short term effects of tennis training on lipid metabolism and to find out if a typical tennis training programme has positive longitudinal effects on cardiovascular risk factors in recreational players.

Methods-The experimental design consisted of an exercise study and a subsequent longitudinal study. In the exercise study the short term metabolic effects of a two hour technically orientated tennis training (TT) session and a running intensive tennis training (RIT) session were investigated in 16 recreational tennis players (eight men: 46 (SD 7) years, 177 (6) $\mathrm{cm}, 81$ (10) kg; and eight women: 44 (5) years, 165 (5) $\mathrm{cm}, 64$ (6) $\mathrm{kg}$ ). In the longitudinal study the long term effects of a six week RIT programme in 22 players (11 men and 11 women) of similar characteristics were compared with those in $\mathbf{1 6}$ control subjects (eight men and eight women). The results of the exercise study (higher lipolytic activity and cardiopulmonary demand, as well as acceptance by the players) led to the RIT method being chosen for all training sessions in the longitudinal study.
\end{abstract}

Results-In RIT, significantly higher values for heart rate (148 (SD 10) $v 124$ (11) beats/minute) and lactate $(2.8$ (1.1) $v 1.5$ (0.6) $\mathrm{mmol} / \mathrm{l}$ ), significantly higher post exercise concentrations of serum glycerol $(0.37(0.15) v 0.29(0.14) \mathrm{mmol} / \mathrm{l})$ and high density lipoprotein cholesterol (1.31 (0.55) $v 1.20(0.50) \mathrm{mmol} / \mathrm{l})$ and a higher acceptance than in TT (15 of the 16 players preferred RIT) were found. During the six week tennis training programme the changes in body weight $(-1.41(1.56) v 0.00$ $(1.50) \mathrm{kg})$ and anaerobic threshold (1.04 $(0.84) v-0.08(0.92) \mathrm{km} / \mathrm{h})$ were significantly different between the training and control group. In the training group several parameters of the lipoprotein profile tended to change in an antiatherosclerotic direction.

Conclusions-The results indicate that typical regular tennis training influences cardiovascular risk factors in a positive manner and can be suggested as an attractive alternative to other current health orientated sports programmes. A more frequent use of running intensive exercises during tennis training is recommended.

(Br 7 Sports Med 1997;31:322-327)
Keywords: tennis training; cardiovascular risk factors; lipid profile; lipolysis

The number of acute changes in lipoproteins after prolonged exercise $\mathrm{e}^{1-4}$ as well as the findings from numerous longitudinal studies ${ }^{5-7}$ point to a specific lipid modulating effect of physical exercise. In the course of different training programmes, a decline in triglycerides, total cholesterol and low density lipoprotein cholesterol (LDL-C) as well as a rise in high density lipoprotein cholesterol (HDL-C) has been shown. These adaptations are related to the regularly increased energy turnover, which comes together with increased hydrolysis of triglycerides and elevated lipid oxidation. ${ }^{89}$ The repeated activation of lipolysis results in a greater breakdown of triglyceride-transporting lipoproteins (chylomicrons and very low density lipoprotein cholesterol) and increases the circulating levels of the antiatherosclerotic compound HDL-C. ${ }^{8}$ Sports that, on the basis of their specific profile of demands (sufficient duration and appropriate intensity), cause high activation of lipolysis, are more likely to induce positive adaptations of the lipoprotein profile. Thus special interest has been directed to examining the extent of lipolysis during exercise of varied intensity ${ }^{10} 11$ and to investigate the short ${ }^{134}$ and long term effects ${ }^{561213}$ of physical exertion on HDL-C levels.

Health orientated and lipid lowering sports programmes are based almost exclusively on typical endurance activities-for example, hiking, jogging, swimming, cycling, and crosscountry skiing. Despite their indisputable value to recreational sportsmen, it is difficult to maintain interest in such programmes. Consequently, many studies have addressed the phenomenon of drop out in health related activities. ${ }^{14-16}$ Enjoyment and satisfaction are important for adherence to exercise programmes. Thus the probability of drop out is very high if the sporting activity is associated with negative emotions such as boredom and dissatisfaction. ${ }^{16}$ Therefore a monotonous endurance work load may not always possess the necessary attraction for lifetime regular involvement in such an activity. Consequently, long term alterations in physical activity and everyday habits often fail to appear.

In contrast, tennis is one of the most attractive and currently popular "lifetime sports", and the number of middle aged and elderly tennis players is constantly growing. The absolute (416 $446 v 1205168)$ and relative $(25 \% v$ $52 \%$ ) number of members of the German Tennis Federation over the age of 35 increased enormously from 1983 to $1993 .{ }^{17}$ Thus the 
Table 1 Physical characteristics of the subjects participating in the exercise study as well as in the training and the control group of the longitudinal study. Values are mean (SD)

\begin{tabular}{llllll}
\hline Subjects & Sex & Age (years) & Height (cm) & Weight (kg) & Body mass index \\
\hline Exercise study & Men $(\mathrm{n}=8)$ & $46(7)$ & $177(6)$ & $81(10)$ & $25.8(1.2)$ \\
& Women $(\mathrm{n}=8)$ & $44(5)$ & $165(5)$ & $64(6)$ & $23.7(2.5)$ \\
Longitudinal study (training group) & Men $(\mathrm{n}=11)$ & $45(7)$ & $175(7)$ & $79(9)$ & $25.9(2.2)$ \\
& Women $(\mathrm{n}=11)$ & $43(4)$ & $166(6)$ & $66(8)$ & $24.0(2.7)$ \\
Longitudinal study (control group) & Men $(\mathrm{n}=8)$ & $47(7)$ & $178(3)$ & $82(4)$ & $25.9(1.1)$ \\
& Women $(\mathrm{n}=8)$ & $44(5)$ & $165(4)$ & $61(7)$ & $22.7(2.2)$ \\
\hline
\end{tabular}

goal of our study was to find out whether regular tennis training is a potential alternative to the usual health related aerobic exercise programmes and if it has a positive effect on cardiovascular risk factors in recreational players. In addition, we compared the short term metabolic responses of two differently designed tennis training sessions. Of special interest were the questions "To what extent is lipolysis activated during a typical tennis training session?" and "Through which training forms can activation of lipolysis be increased?" From the answers to these questions, we expected to find specific indications for the development of preventive health orientated tennis training programmes.

\section{Methods}

SUBJECTS

A total of 46 healthy middle aged recreational players participated in the study. Thirty eight subjects were included in the data analysis (for

\begin{tabular}{|c|c|c|}
\hline & $\begin{array}{l}\text { Technical } \\
\text { training }\end{array}$ & $\begin{array}{c}\text { Running intensive } \\
\text { training }\end{array}$ \\
\hline \multicolumn{3}{|l|}{ General characteristics } \\
\hline Stroke frequency & $\downarrow$ & $\uparrow$ \\
\hline Running distances & $\downarrow$ & 4 \\
\hline Rest periods & 4 & $\downarrow$ \\
\hline Technical corrections & $\uparrow$ & $\downarrow$ \\
\hline Specific details & $\begin{array}{c}\text { Warm up } \\
\text { (focus on technique) }\end{array}$ & $\begin{array}{l}\text { Warm up } \\
\text { (focus on footwork) }\end{array}$ \\
\hline $15 \mathrm{~min}$ & $\begin{array}{l}\text { Players in line } \\
\text { Pro is feeding } 3 \text { balls } \\
\text { for each player } \\
\text { (without running) }\end{array}$ & $\begin{array}{c}\text { Players in line } \\
\text { Pro is feeding } 1 \text { ball } \\
\text { for each player } \\
\text { ( } 8 \text { m running distance) }\end{array}$ \\
\hline $45 \mathrm{~min}$ & $\begin{array}{c}\text { Ballmachine } \\
\text { programme } \\
\text { Forehand/backhand } \\
19 \text { balls/min }\end{array}$ & $\begin{array}{c}\text { Ballmachine } \\
\text { programme } \\
\text { Forehand/backhand } \\
22 \text { balls/min }\end{array}$ \\
\hline $115 \mathrm{~min}$ & $\begin{array}{c}\text { Match training } \\
\text { Doubles }\end{array}$ & $\begin{array}{c}\text { Match training } \\
\text { Singles baseline rallys }\end{array}$ \\
\hline $120 \mathrm{~min}$ & & \\
\hline
\end{tabular}

Figure 1 General characteristics and specific details of the two tennis training sessions of the exercise study. criteria, see below). Table 1 shows the physical characteristics of the different subgroups of subjects. No significant differences were found for body mass index between subgroups. Playing experience in the whole group was 4.1 (2.0) years. The usual playing frequency was 2.1 (0.8) hours/week during summer and 0.9 (0.7) hours/week during winter. All subjects in the exercise study group were also members of the longitudinal training group. Subjects were thoroughly informed about the experimental procedure and gave written consent. The study was approved by the local ethics committee.

\section{PROCEDURE}

The experimental design consisted of an exercise study and a subsequent longitudinal study. First we compared the short term metabolic effects of a two hour technically orientated tennis training (TT) session with those of a running intensive tennis training (RIT) session. According to the results of the exercise study (greater increase in lipolysis and cardiopulmonary demand, as well as greater acceptance by the players in RIT), we designed a six week RIT programme and analysed its longitudinal effects on selected cardiovascular risk factors.

For the exercise study, 16 subjects (table 1 ) participated in two differently designed practice sessions, each lasting 120 minutes (3-5 $\mathrm{pm}$ ), in groups of four players with one coach. The sessions consisted of TT or RIT. The time structure of the training units was identical (fig 1). The two training units differed with respect to number and frequency of stroke production, running distances for stroke preparation, duration of rest periods, and number of technical corrections (fig 1). The study was carried out on two consecutive weekends during the summer on outdoor clay courts. The order of the two training sessions was randomised. Environmental conditions were measured at the beginning of the training units and differed only marginally between the four experimental days (temperature $28-31^{\circ} \mathrm{C}$; humidity 30 $45 \%$ ). Subjects were asked to refrain from exercise and to keep to the same prescribed diet the day before each trial. During the test days, subjects received a standardised breakfast at 8 am and a prescribed carbohydrate-rich lunch at $1230 \mathrm{pm}$ (men: $3200 \mathrm{~kJ}$; women: $2500 \mathrm{~kJ}$ ) in order to simulate often recommended pretraining conditions. Water intake during training was allowed ad libitum. Heart rate was monitored in 15 second intervals using a Polar Sport-Tester (Kempele, Finland). After each part of the exercise (fig 1) perceived exertion $(\mathrm{RPE})^{18}$ was registered, and capillary blood samples were taken for blood lactate analysis. 
Pre- and post-exercise serum concentrations of free fatty acids (FFA), glycerol, triglycerides, HDL-C and its subfractions $\mathrm{HDL}_{2}-\mathrm{C}$ und $\mathrm{HDL}_{3}-\mathrm{C}$, as well as haematocrit were measured. At the end of both training units, participants were requested to record their preferred method of training.

For the longitudinal study, 30 players participated in a six week RIT programme with three 90 minute sessions per week. Sixteen additional players served as control subjects (table 1). They were asked to maintain their usual habits during the time of the study, which was checked by questionnaire. Subjects were assigned to the two groups according to their ability to participate in all training units. In the training group, the sessions were carried out by small groups of four players with one trainer per court. All participants completed the same exercises. Average percentage participation was 94. We attempted to reach a high work/rest ratio and followed the general characteristics of RIT presented in fig 1 .

Before and after the training programme we measured body weight and serum levels of total cholesterol, $\mathrm{HDL}-\mathrm{C}, \mathrm{HDL}_{2}-\mathrm{C}, \mathrm{HDL}_{3}-\mathrm{C}$, LDL-C and triglycerides twice after an overnight fast. Measurements were recorded three and nine days before the first and after the last training unit. The average of the two pre- and post-training values was used for the longitudinal comparison. No information about the menstrual cycle was gathered since there were exactly eight weeks between pre- and posttraining measurements.

Endurance capacity was evaluated one week before the first, and immediately after the last estimation of lipoprotein profile by means of an incremental running field test carried out on a $400 \mathrm{~m}$ track at the same time and under identical nutritional conditions. ${ }^{19}$ The initial work load was $2.0 \mathrm{~m} / \mathrm{s}$ and the work rate was increased by $0.4 \mathrm{~m} / \mathrm{s}$ every five minutes until voluntary exhaustion. Arterialised blood samples were taken from a hyperaemic earlobe in half minute breaks between the work loads. We determined the anaerobic threshold as running speed $(\mathrm{km} / \mathrm{h})$ at the level of $4 \mathrm{mmol} / \mathrm{l}$ blood lactate concentration. ${ }^{19}$

Changes in nutritional and other lifestyle habits during the training period were assessed anonymously after the investigation by questionnaire. We inquired by means of a three point scale (not true, partly true, very true) whether the participants had changed their nutritional habits and the amount of tennis
Table 2 Heart rate, capillary lactate, and perceived exertion (RPE) during two different tennis training sessions. Values are mean (SD)

\begin{tabular}{lcc}
\hline Exercise study & $\begin{array}{l}\text { Technical training } \\
(n=16)\end{array}$ & $\begin{array}{l}\text { Running intensive } \\
\text { training }(n=16)\end{array}$ \\
\hline Heart rate (beats/min) & $124(11)$ & $148(10)^{\star}$ \\
Lactate (mmol/l) & $1.5(0.6)$ & $2.8(1.1)^{\star}$ \\
RPE & $11.6(2.6)$ & $13.7(2.4)^{\star}$ \\
\hline
\end{tabular}

${ }^{\star}$ Significantly different from technical training $(P \leqslant 0.05)$.

played. In our data analysis, only subjects who had maintained their nutritional habits and increased their tennis playing considerably during the training period $(n=22)$ were considered. The other eight subjects were excluded from analysis. In the control group, no changes with respect to the amount of tennis or other lifestyle factors were recorded.

\section{ANALYSES AND CALCULATIONS}

Serum concentrations of FFA, glycerol, triglycerides, total cholesterol, HDL-C, and $\mathrm{HDL}_{3}-\mathrm{C}$ were measured enzymatically by means of the Cobas-Bio centrifugal analyser (Hoffmann-La Roche, Basel, Switzerland). Capillary blood samples were analysed for lactate (Eppendorf-Analyser 5060, Hamburg, Germany). The Sysmex Dualdilutor (Digitana AG, Hamburg, Germany) was used for haematological analysis. Precision and accuracy of the applied procedures was verified by consideration of the usual guidelines for internal and external laboratory control.

Serum was prepared by standard methods, fractionated before analysis, and either frozen at $-20^{\circ} \mathrm{C}$ (FFA, glycerol, triglycerides and total cholesterol analysis) or stored at $+4^{\circ} \mathrm{C}$ (HDL-C and $\mathrm{HDL}_{3}-\mathrm{C}$ analysis). Commercial test kits were used for analysis of FFA (Wako, Neuss, Germany), glycerol (Boehringer, Mannheim, Germany), triglycerides, and total cholesterol (Hoffmann-La Roche). HDL-C and $\mathrm{HDL}_{3}-\mathrm{C}$ were fractionated by precipitation before analysis and assayed fresh after a maximum length of storage of two days. We used two precipitation reagents (Immuno AG, Wien, Austria) which contained polyethylene glycol of different concentration. The addition of the two polyethylene glycol solutions resulted in selective precipitation of lipoprotein fractions. After centrifugation, the supernatants contained either HDL-C or $\mathrm{HDL}_{3}-\mathrm{C}$. $\mathrm{HDL}_{2}-\mathrm{C}$ (difference between HDL-C and $\mathrm{HDL}_{3}-\mathrm{C}$ ) and LDL-C concentrations were calculated. ${ }^{20}$

Table 3 Pre $(0 \mathrm{~min})$ and post exercise values $(120 \mathrm{~min})$ as well as mean changes in serum lipids and lipoproteins during two different tennis training units. Values are mean $(S D)$

\begin{tabular}{|c|c|c|c|c|c|c|c|}
\hline \multirow{2}{*}{$\begin{array}{l}\text { Exercise study } \\
\text { (mmol/l) }\end{array}$} & \multicolumn{3}{|c|}{ Technical training $(n=16)$} & \multicolumn{3}{|c|}{ Running intensive training $(n=16)$} & \multirow{2}{*}{$\begin{array}{l}\text { P value } \\
\text { (training } \times \text { time) }\end{array}$} \\
\hline & $0 \mathrm{~min}$ & $120 \mathrm{~min}$ & Mean $(S D)$ & $0 \mathrm{~min}$ & $120 \mathrm{~min}$ & Mean $(S D)$ & \\
\hline FFA & $0.88(0.39)$ & $1.83(0.57)^{\star}$ & $0.95(0.57)$ & $0.94(0.27)$ & $2.16(0.63)^{\star}$ & $1.22(0.62)$ & 0.095 \\
\hline Glycerol & $0.13(0.07)$ & $0.29(0.14)^{\star}$ & $0.16(0.13)$ & $0.13(0.04)$ & $0.37(0.15)^{\star} \dagger$ & $0.24(0.15)$ & 0.046 \\
\hline Triglycerides & $2.14(1.05)$ & $1.78(0.72)^{\star}$ & $-0.36(0.51)$ & $2.12(0.81)$ & $1.55(0.41)^{\star}$ & $-0.57(0.59)$ & 0.122 \\
\hline HDL-C & $1.13(0.49)$ & $1.20(0.50)^{\star}$ & $0.07(0.10)$ & $1.15(0.50)$ & $1.31(0.55)^{\star} \dagger$ & $0.16(0.09)$ & 0.050 \\
\hline $\mathrm{HDL}_{2}-\mathrm{C}$ & $0.46(0.24)$ & $0.50(0.24)^{\star}$ & $0.04(0.14)$ & $0.47(0.25)$ & $0.58(0.21)^{\star}$ & $0.11(0.10)$ & 0.095 \\
\hline $\mathrm{HDL}_{3}-\mathrm{C}$ & $0.67(0.25)$ & $0.70(0.30)$ & $0.03(0.15)$ & $0.68(0.28)$ & $0.73(0.33)$ & $0.05(0.15)$ & 0.919 \\
\hline
\end{tabular}

FFA, free fatty acid; HDL-C, high density lipoprotein cholesterol.

${ }^{\star}$ Significantly different from 0 min for both training sessions $(P \leqslant 0.05)$.

† Significantly different from technical training $(P \leqslant 0.05)$. 
Table 4 Pre and post training values as well as mean longitudinal changes in lipid profile, body weight and anaerobic threshold (AT) during a six week running intensive tennis training programme. Values are mean (SD)

\begin{tabular}{|c|c|c|c|c|c|c|c|}
\hline \multirow[b]{2}{*}{ Longitudinal study } & \multicolumn{3}{|c|}{ Training group $(n=22)$} & \multicolumn{3}{|c|}{ Control group $(n=16)$} & \multirow{2}{*}{$\begin{array}{l}\text { Pvalue } \\
\text { (group x time) }\end{array}$} \\
\hline & Pre & Post & Mean $(S D)$ & Pre & Post & Mean (SD) & \\
\hline Chol (mmol/l) & $5.89(1.08)$ & $5.59(0.92)$ & $-0.30(0.51)$ & $5.90(0.70)$ & $5.95(0.89)$ & $0.05(0.62)$ & 0.082 \\
\hline $\mathrm{HDL}-\mathrm{C}(\mathrm{mmol} / \mathrm{l})$ & $1.22(0.42)$ & $1.23(0.38)$ & $0.01(0.14)$ & $1.25(0.33)$ & $1.27(0.38)$ & $0.02(0.15)$ & 0.572 \\
\hline $\mathrm{HDL}_{2}-\mathrm{C}(\mathrm{mmol} / \mathrm{l})$ & $0.37(0.20)$ & $0.41(0.17)$ & $0.04(0.09)$ & $0.41(0.19)$ & $0.42(0.21)$ & $0.01(0.10)$ & 0.459 \\
\hline $\mathrm{HDL}_{3}-\mathrm{C}(\mathrm{mmol} / \mathrm{l})$ & $0.85(0.24)$ & $0.82(0.22)$ & $-0.03(0.09)$ & $0.84(0.21)$ & $0.85(0.22)$ & $0.01(0.13)$ & 0.174 \\
\hline $\mathrm{LDL}-\mathrm{C}(\mathrm{mmol} / \mathrm{l})$ & $4.13(1.17)$ & $4.01(1.07)$ & $-0.12(0.42)$ & $4.06(0.78)$ & $4.09(0.91)$ & $0.03(0.54)$ & 0.319 \\
\hline $\mathrm{TG}(\mathrm{mmol} / \mathrm{l})$ & $1.27(0.64)$ & $1.11(0.39)$ & $-0.16(0.35)$ & $1.25(0.49)$ & $1.28(0.36)$ & $0.03(0.41)$ & 0.114 \\
\hline Chol/HDL-C & $5.34(2.08)$ & $4.98(1.67)$ & $-0.36(1.04)$ & $5.08(1.72)$ & $5.05(1.83)$ & $-0.03(0.42)$ & 0.151 \\
\hline LDL-C/HDL-C & $3.88(2.10)$ & $3.65(1.68)$ & $-0.23(0.53)$ & $3.58(1.52)$ & $3.54(1.62)$ & $-0.04(0.34)$ & 0.385 \\
\hline $\mathrm{HDL}_{2}-\mathrm{C} / \mathrm{HDL}_{3}-\mathrm{C}$ & $0.43(0.16)$ & $0.52(0.17)$ & $0.09(0.15)$ & $0.49(0.22)$ & $0.49(0.21)$ & $0.00(0.17)$ & 0.118 \\
\hline Body weight (kg) & $74.8 \quad(12.2)$ & $73.4(11.3)^{\star}$ & $-1.41(1.56)$ & $73.1 \quad(12.3)$ & $73.1 \quad(12.8)$ & $0.00(1.50)$ & 0.003 \\
\hline AT $(\mathrm{km} / \mathrm{h})$ & $9.30(1.78)$ & $10.34(1.41)^{\star}$ & $1.04(0.84)$ & $9.53(2.10)$ & $9.45(1.73)$ & $-0.08(0.92)$ & 0.000 \\
\hline
\end{tabular}

Chol, cholesterol; HDL-C, high density lipoprotein cholesterol; LDL-C, low density lipoprotein cholesterol; TG, triglycerides.

* Significantly different from pre training $(P \leqslant 0.05)$

\section{STATISTICAL ANALYSIS}

Data are presented as mean (SD). Statistical analysis was carried out using two way analysis of variance for repeated measures (tables 3 and $4)$. In the case of significance, simple effects were verified by Newman-Keuls test. Heterogeneous variances were adjusted (Huynh-Feldt and Box procedure). Additional analysis was performed using paired Student's $t$ test (table 2). Selected correlations were calculated according to the Pearson procedure (fig 2). Significance levels were set at $P \leqslant 0.05$.

\section{Results}

In the exercise study, blood lactate, heart rate and RPE differed significantly during TT and RIT (table 2). Serum FFA and glycerol values increased and triglycerides decreased in both exercise types between the measured time points. Increases in glycerol and HDL-C were significantly higher in RIT than in TT (table 3). Plasma volume decreased in both training sessions (TT: -3.9 (2.9)\%; RIT: -2.4 (2.3)\%) calculated according to the formula of Van Beaumont. $^{21}$ Fifteen of the sixteen subjects chose RIT as their preferred training method.

Table 4 shows the results of the longitudinal study. The six week tennis training programme
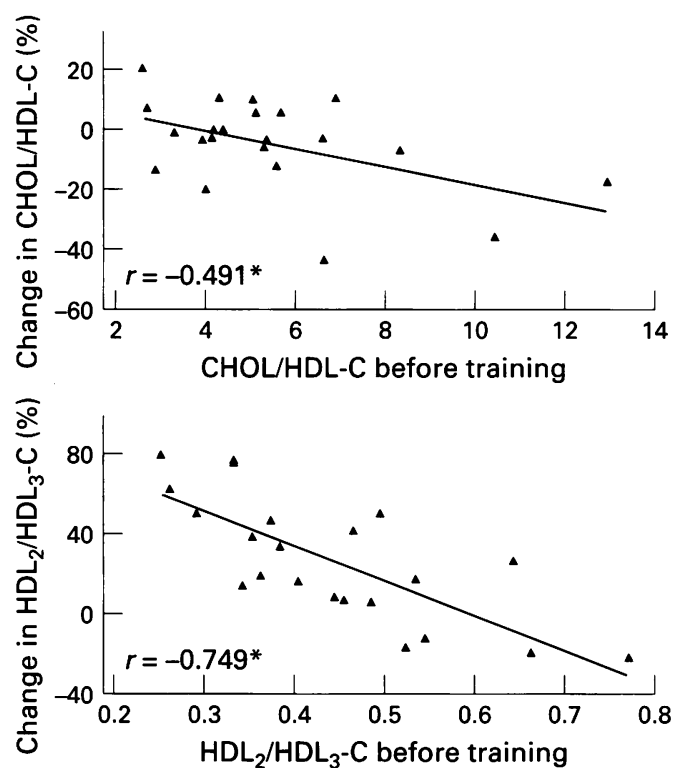

led to a decrease in body weight and an increase in the anaerobic threshold in the training group. Both changes were significantly different from those in the control group. Total cholesterol, triglycerides, and the total cholesterol/HDL-C ratio tended to decrease in the training group, and a rise in the $\mathrm{HDL}_{2}-\mathrm{C} /$ $\mathrm{HDL}_{3}-\mathrm{C}$ ratio was noticeable. The changes in the lipoprotein profile were not significantly different between training and control group.

The correlation of selected parameters shows a significant connection $(P \leqslant 0.05)$ between the initial ratios of total cholesterol/ $\mathrm{HDL}-\mathrm{C}$ and $\mathrm{HDL}-\mathrm{C}_{2} \mathrm{HDL}_{3}-\mathrm{C}$ ratios and the relative extent of adaptation. Changes in both ratios were largely independent of decreases in body weight and increases in the anaerobic threshold (fig 2).

\section{Discussion}

The discussion is focused on the question of whether tennis can have a positive effect on cardiovascular risk factors ${ }^{22}$ and what kind of training should be recommended to achieve this goal. Therefore, we first investigated the extent of lipolysis during two differently designed tennis training units. Regularly increasing lipolysis is associated with raised lipid oxidation, ${ }^{23}$
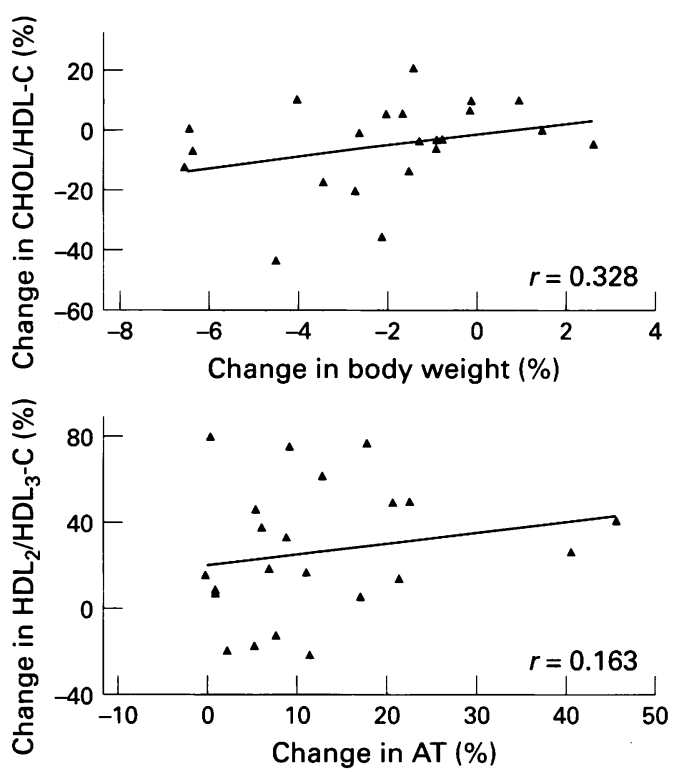

Figure 2 Correlation and linear regression analysis between pre-training values and mean relative longitudinal changes in selected variables during a six week running intensive tennis training programme. CHOL, cholesterol; $H D L-C$, high density lipoprotein cholesterol; $A T$, anaerobic threshold. 
which can result in a positive modulation of the lipid profile. ${ }^{8}$ We expected to obtain from the exercise study important information for the design of the longitudinal training programme.

In both sessions of the exercise study, serum concentrations of FFA and glycerol increased significantly by two- to three-fold (table 3). Similar findings have been frequently reported for continuous endurance exercises..$^{101124}$ Lipolysis is increased primarily through the higher energy turnover and an overall catecholamine induced activation. ${ }^{25}$ Our data show that the applied tennis training is comparable with typical endurance sports with respect to the extent of lipolysis. As a result of the increased availability of FFA in the serum, a greater turnover in the muscle cell and increased oxidation of lipids can be assumed. ${ }^{23}$ Precise conclusions on the quantitative participation of fat metabolism in energy supply cannot be made on the basis of the data obtained. However, early studies showed that, during intermittent exercise, favourable conditions exist for the contribution of lipids to oxidative metabolism because of the more efficient oxygen reloading of myoglobin stores during the breaks between physical demands. ${ }^{26}$ Thus we suggest that the long duration, moderate intensity and intermittent work load of typical tennis training sessions forms an excellent basis for lipid metabolism. ${ }^{1026}$

In RIT the increase in serum FFA and glycerol and the decrease in triglycerides is more pronounced. Differences in plasma volume changes can be excluded as a factor affecting results because the decrease in plasma volume in RIT was similar to that in TT. ${ }^{21}$ Glycerol in particular shows a statistically significant higher increase in RIT (table 3). The amount of glycerol appearing in the venous blood is normally used as a guide to changes in adipose tissue lipolysis. ${ }^{24}$ Evidently, the increased physical demands (table 2) are associated with an increase in lipolysis. The low concentrations of blood lactate found during both exercise forms indicate that the intensity threshold for lipolysis inhibition was not exceeded. Earlier studies proved that, at different work loads up to $70 \% \quad \dot{\mathrm{V}} \mathrm{O}_{2} \max$, lipolysis increases during exercise. ${ }^{10}$ Thus, with regard to the most extensive activation of lipid metabolism, favourable conditions were found in RIT.

Acute changes in HDL-C occurred only in RIT (table 3). The greater activation of lipolysis and the more pronounced decrease in serum triglycerides in RIT may be connected with the increase in HDL-C and $\mathrm{HDL}_{2}-\mathrm{C}$ (table 3). In the case of lipolytic breakdown of triglyceride rich lipoproteins, particle components (cholesterol, phospholipids and C-apoproteins) can be transferred to $\mathrm{HDL}_{3}$ with subsequent conversion to $\mathrm{HDL}_{2}{ }^{27}$ Exercise-induced effects of HDL-C have been reported in other studies. ${ }^{1-4}$ The absence of changes in HDL is usually accredited to differences in duration and intensity of physical demand. ${ }^{1}$ Our data confirm that during tennis training a minimal work load has to be exceeded in order to achieve an acute increase in circulating HDL-C particles. ${ }^{3}$
Overall, RIT is the recommended form of training for reducing cardiovascular risk factors because it leads to more pronounced lipolysis and may affect lipid and lipoprotein metabolism in an antiatherogenic way. Our findings on heart rate show that the work load in solely technical training is too low to induce clear cardiovascular effects. However, efficient running intensive exercises can only be achieved if tennis technique is already sufficiently developed. Thus we recommend a combination of technically oriented and running intensive training. However, the latter should be given progressively more attention by tennis players and coaches as players improve. Another reason for this is the acceptance level of the respective training forms by the participants. Fifteen of the sixteen players chose RIT as the preferred form of training. Personal and motivational factors have been proven to be very important for ensuring adherence to exercise programmes. ${ }^{14-16}$

In the longitudinal study, we investigated the question of whether a typical tennis training programme that causes a significant increase in the usual amount of exercise undertaken by recreational players can induce a positive change in cardiovascular risk factors. Based on earlier findings, a health promoting influence of tennis seems to be likely. In an epidemiological study, Vodak $e t a l^{28}$ found an independent effect of vigorous tennis playing over decades on the lipid profile. The striking activation of lipid metabolism during our exercise study also points towards long term alterations in lipid profile in cases of regular repetition of individual training units. Despite the typical rebounds of acute exercise responses, long term adaptation of lipoproteins is suggested to be the result of continuously occurring single-exercise effects. ${ }^{1}$ Consequently, because of the larger short term metabolic effects, we chose RIT as the main training method during the longitudinal study.

In the course of this six week tennis training programme, we observed a significant reduction in body weight and a significant increase in anaerobic threshold (table 4). In addition, several components of the lipid profile tended to show antiatherogenic adaptations. The extent of these changes is comparable with findings from other longitudinal studies. In a metaanalysis of 66 training studies representing 2925 subjects, almost the same results were calculated. ${ }^{7}$ Despite the overall positive development of the lipid profile, the changes were not significantly different from those in the control group (table 4). This might be due to the limited number of subjects and the comparably short duration of the training period. ${ }^{29}$ In the present study the six week time period was presumably too short to cause more striking effects. The significantly reduced body weight and the improvement in anaerobic threshold shows that these adaptations occur earlier (table 4). Both aspects are of immense importance in health orientated considerations and indicate the value of on court conditioning tennis training programmes for primary prevention of cardiovascular diseases. ${ }^{22}$

A detailed analysis of changes in the lipid profile shows a positive tendency for total 
cholesterol and triglycerides as well as for the ratios of total cholesterol/HDL-C and $\mathrm{HDL}_{2}-$ $\mathrm{C} / \mathrm{HDL}_{3}-\mathrm{C}$ (table 4). Considering the results of the exercise study (table 3), the small effect on HDL-C during the longitudinal study is surprising. Other authors describe a significant increase in HDL-C, which occurred after eight ${ }^{5}$ or ten weeks. ${ }^{6}$ However, in some longitudinal studies a training induced HDL-C augmentation was not found. ${ }^{12}{ }^{13}$ One reason for these differing results is the duration of the training programme. For example, Peltonen et $a l^{6}$ reported changes in the longitudinal course of HDL-C concentration with a significant increase occurring only after ten weeks.

Although the HDL-C level remained largely unchanged, we found a decline in $\mathrm{HDL}_{3}-\mathrm{C}$ and an increase in $\mathrm{HDL}_{2}-\mathrm{C}$ (table 4). Similar results were obtained by Nye $e t a l^{13}$ during a ten week long training programme. These significant shifts are of antiatherosclerotic importance because an improved post-prandial triglyceride clearance in subjects with an increased $\mathrm{HDL}_{2}-\mathrm{C}$ fraction has been shown. ${ }^{2}$ The decline in total cholesterol (table 4) can be related to the reported changes due to the $\mathrm{HDL}_{2}$ mediated removal of cholesterol from the periphery. ${ }^{8} \mathrm{~A}$ small correlation $(r=0.390, \mathrm{P} \leqslant 0.05)$ between decrease in total cholesterol and increase in $\mathrm{HDL}_{2}-\mathrm{C} / \mathrm{HDL}_{3}-\mathrm{C}$ ratio highlights this point.

The relative alterations in the total cholesterol/ $\mathrm{HDL}-\mathrm{C}$ and $\mathrm{HDL}_{2}-\mathrm{C} / \mathrm{HDL}_{3}-\mathrm{C}$ ratios negatively correlate with their initial values (fig 2 ). Consequently, it appears that, the worse the entrance level of the subjects, the better will be the relative benefit of such tennis training. It is notable that the correlation is primarily increased by two extremely high pre-exercise values. The reduction of these pathologically high total cholesterol/HDL-C ratios is particularly desirable from a health point of view because of their predictive value for the incidence of coronary heart disease. ${ }^{30}$ The adaptations described are largely independent of the relative weight loss of the participants (fig 2). This can be seen as an indication that the adaptations are primarily the result of the increased physical and metabolic activity that occurs during tennis training rather than being side effects of the training programme. Thus a direct positive effect of a regular running intensive tennis training on the lipid profile appears to be possible.

In summary, the results of this study indicate that a tennis training programme undertaken by middle aged recreational players can affect several cardiovascular risk factors in a positive way, and thus can be seen as an attractive alternative to the usual health orientated sports programmes. A reduction in body weight, an increase in physical performance, and a tendency for positive antiatherogenic effects on the lipid profile can already be achieved after a six week training period. Extending the duration of the programme would appear to have potential for achieving more striking effects on HDL-C. With respect to the forms of training, we suggest that, not only from a metabolic point of view but also because of the high acceptance, those forms that require a high work/rest ratio and maintain an aerobic level of intensity should be recom- mended. Tennis colleges and coaches should be encouraged to offer attractive metabolically demanding on court training programmes.

1 Angelopoulos TJ, Robertson RJ, Goss FL, Metz KF, La Porte RE. Effect of repeated exercise bouts on high density $\mathrm{HDL}_{3}$-C. Int $\mathcal{F}$ Sports Med 1993;14:196-201.

2 Berg A, Johns J, Baumstark M, Kreutz W, Keul J. Changes in HDL subfractions after a single, extended episode of physical exercise. Atherosclerosis 1983;47:231-40.

3 Hicks AL, Mac Dougall JD, Muckle TJ. Acute changes in high-density lipoprotein cholesterol with exercise of different intensities. ₹ Appl Physiol 1987;63:1956-60.

4 Kuusi T, Kostiainen E, Vartiainen E, Pitkanen L, Ehnholm $\mathrm{C}$, Korhonen $\mathrm{HJ}$, et al. Acute effects of marathon running on levels of serum lipoproteins and androgenic hormones in healthy males. Metabolism 1984;33:527-31.

5 Farrell PA, Barboriak J. The time course of alterations in plasma lipid and lipoprotein concentrations during eight weeks of endurance training. Artherosclerosis 1980;37:231-8.

6 Peltonen P, Marniemi J, Hietanen E, Vuori I, Ehnholm C. Changes in serum lipids, lipoproteins, and heparin releasable lipolytic enzymes during moderate physical training in man: a longitudinal study. Metabolism 1981;30: 518-26.

7 Tran ZV, Weltman A, Glass GV, Mood DP. The effects of exercise on blood lipids and lipoproteins: a meta-analysis of studies. Med Sci Sports Exerc 1983;15:393-402.

8 Berg A, Halle M, Baumstark M, Frey I, Keul J. Einfluß und Wirkungsweise der körperlichen Aktivität auf Lipid- und Lipoproteinstoffwechsel. Deutsche Zeitschrift für Sportmedizin 1991;42:224-31.

9 Havel RJ. Some influences of the sympathetic nervous system and insulin on mobilization of fat from adipose tissue: studies of the turnover rates of free fatty acids and glycerol. Ann NY Acad Sci 1965;131:91-101.

10 Pruett EDR. FFA mobilization during and after prolonged severe muscular work in men. $\mathcal{f}$ Appl Physiol 1970;29:809_ 15.

11 Osness WH, Blake B, Gordon ES, Rankin J, Nagle F, Breck W, Dempsey J. Plasma fatty-acid-glycerol concentration changes during steady state exercise of varied intensity. Medicina Dello Sport 1971;11:157-66.

12 Brownell KD, Bachorik PS, Ayerle RS. Changes in plasma lipid and lipoprotein levels in men and women after a pro-
gram of moderate exercise. Circulation 1982;65:477-84.

13 Nye ER, Carlson K, Kirstein P, Rössner S. Changes in high density lipoprotein subfractions and other lipoproteins induced by exercise. Clin Chim Acta 1981;113:51-7.

14 Dishman RK. Medical psychology in exercise and sport. Med Clin North Am 1985;69:123-42.

15 McAuley E. Efficacy, attributional, and affective responses to exercise participation. Fournal of Sport and Exercise Psychology 1991;13:382-93.

16 Wankel LM. Personal and situational factors affecting exercise involvement: the importance of enjoyment. Res $Q$ Exerc Sport 1985;56:275-82.

17 Sklorz M. Stellung und Bedeutung der Seniorinnen und Senioren im Breitensport. In: Hölting N, Weber K, Funhoff $\mathrm{H}$, ed. Tennis im höheren Lebensalter aus interdisziplinärer Sicht. Hamburg: Czwalina, 1995:169-74.

18 Borg G. Perceived exertion: a note on history and methods. Med Sci Sports 1973;5:90-3.

19 Heck H, Mader A, Liesen H, Hollmann W. Vorschlag zur Standardisierung leistungsdiagnostischer Untersuchungen auf dem Laufband. Deutsche Zeitschrift für Sportmedizin 1982;33:304-7.

20 Friedewald WF, Levy RI, Fredrickson DS. Estimation of LDL-cholesterol concentration without use of the preparaLDL-cholesterol concentration without use of the

21 Van Beaumont W. Evaluation of hemoconcentration from hematocrit measurements. F Appl Physiol 1972;32:712-13.

22 Farmer JA, Gotto AM. Risk factors for coronary artery disease. In: Braunwald E, ed. Heart disease. A textbook of cardiovascular medicine. Philadelphia, London, Toronto, Montreal, Sydney, Tokyo: Saunders, 1992:1125-57.

23 Havel RJ, Naimark A, Borchgreriuk CF. Turnover rate and oxidation of free fatty acids of blood plasma in man during exercise: studies during continuous infusion of palmitate-1C14. F Clin Invest 1963;42:1054-63.

24 Johnson RH, Walton JL, Krebs HA, Williamson DH. Metabolic fuels during and after severe exercise in athletes and non-athletes. Lancet 1969;II:452-5.

25 Goodman HM, Bray GA. Role of thyroid hormones in lipolysis. Am F Physiol 1966;210:1053-8.

26 Essen B. Studies on the regulation of metabolism in human skeletal muscle using intermittent exercise as an experi-
mental model. Acta Physiol Scand 1978;454(suppl):3-32.

27 Dufaux B, Assmann G, Hollmann W. Plasma lipoproteins and physical activity: a review. Int 7 Sports Med 1982;3:12336.

28 Vodak PA, Wood PD, Haskell WL, Williams PT. HDLcholesterol and other plasma lipid and lipoprotein concentrations in middle-aged male and female tennis players. Metabolism 1980;29:745-52.

29 Sedgewick AW, Brotherhood JR, Harris-Davidson A, Taplin RE, Thomas DW. Long term effects of physical training programme on risk factors for coronary heart disease in otherwise sedentary men. BMf 1980;281:7-10.

30 Assmann G. Lipid metabolism disorders and coronary heart disease. Primary prevention, diagnosis and therapy guidelines for general practice. München: MMV Medizin, 1993. 